\title{
Research of the Tool Velocity and Product Shape Aspects of the Hot Radial Rolling of C45 Steel Rings
}

\author{
Piotr Surdacki ${ }^{*}$, Andrzej Gontarz', Grzegorz Winiarski ${ }^{1}$, Grzegorz Samołyk ${ }^{1}$ \\ 1 Mechanical Faculty, Lublin University of Technology, ul. Nadbystrzycka 36, 20-618 Lublin, Poland \\ * Corresponding author's email: piotr.surdacki@pollub.pl
}

\begin{abstract}
The control of product shape and dimensions creates some problems in hot ring rolling. In the rolling process, material flows both circumferentially and axially, which leads to increased ring height. Changes in shape and dimensions of ring cross section depend on several process parameters, which makes it difficult to predict ring diameter. This paper presents the results of a study investigating the hot radial rolling process for C45 steel rings in terms of the effect of main roll feed speed on product geometry. It was found that the application of a higher feed speed of the main roll and thus of a greater ratio between this speed and circumferential speed of the main roll led to increased axial material flow and reduced cross-sectional defect known as "fishtail". Machining losses generated due to cross-sectional defects were also determined. Results were used to determine the feed speed to circumferential speed ratio ensuring the lowest possible cross-sectional defect and material consumption.
\end{abstract}

Keywords: ring rolling process, FEM model, experimental research, process parameters

\section{INTRODUCTION}

Hot ring rolled products are widely used in numerous structures, from small bearings to large parts used in automotive, railway, power or chemical industries. These rings are characterised by a high diameter to cross section ratio. Other forming techniques for similar parts [1-3] are not as effective as the rolling of ring-shaped semi-finished products with the use of specially designed rolling mills.

There are two main ring rolling processes: radial ring rolling (Fig. 1a) and radial-axial ring rolling (Fig. 1b). In the radial ring rolling process, the cross section of a workpiece is reduced in the radial direction. A ring 3 is put on a mandrel 2 . The cross section of the ring is reduced by feed speed of a main roll 1 moving with a speed $V_{l}$. The main roll is also rotated with a speed $n_{l}$, which makes the ring and mandrel rotate continuously about their axes. Rolling mills are usually equipped with calibrating rolls 4 for workpiece support and calibration.
The radial-axial ring rolling process (Fig. 1b) is performed with the use of additional conical rolls 5 to ensure the required ring height by constraining axial flow of material (along the $Z$ axis). The cross section obtained in this process is rectangular with its width being equal to the distance between the active surfaces of the main roll and mandrel, while its height is equal to the distance between the active surfaces of the conical rolls.

In radial ring rolling, it is more difficult to control the shape and dimensions of rolled rings (Fig. 1a). In this process the material flows both circumferentially, which causes increase in ring diameter, and axially, which causes increase in workpiece height. The only parameter under control in this process is the final width of the cross section, which is equal to the final distance between the active surfaces of the main roll and the mandrel. The axial flow of material is uncontrolled and depends on material properties and process parameters. Due to no constraints on axial flow of material, the cross section of the rolled ring is not rectangular. Metal flow is usually rapid 
(a)

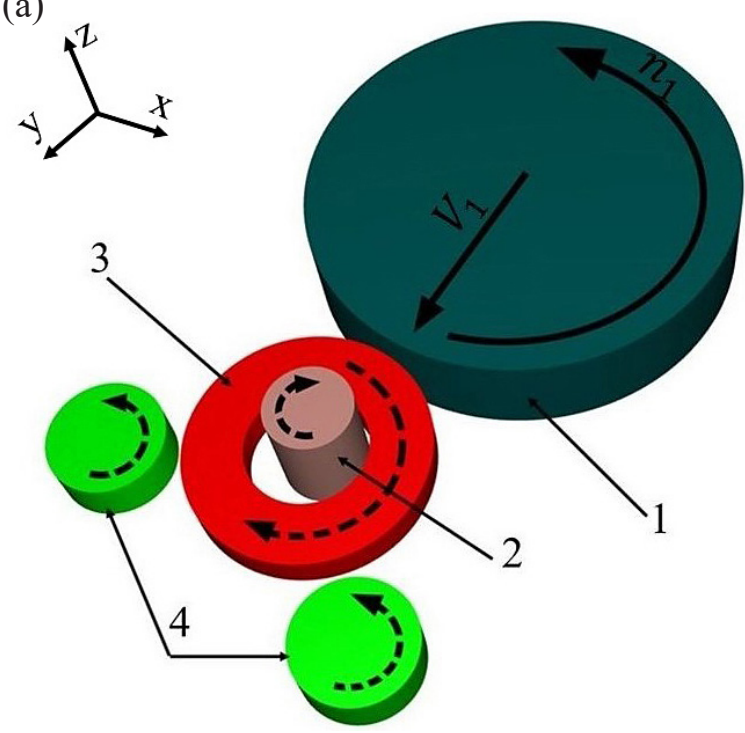

(b)

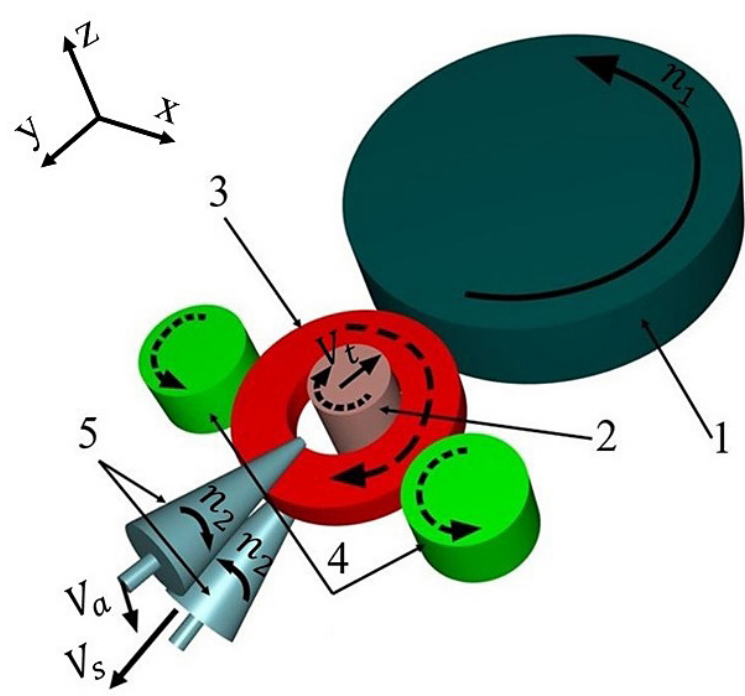

Fig. 1. Schematic representation of the ring rolling process: (a) radial ring rolling, (b) radial-axial ring rolling; 1 - main roll, 2 - mandrel, 3 - ring, 4 - conical rolls, 5 - calibrating rolls

in the vicinity of the tools (main roll and mandrel), which leads to the formation of an hourglass-like shape of the cross section. This shape is considered to be a defect. In the literature of the subject the defect is known as "fishtail" and it is described by a coefficient measured as a ratio of the difference between maximum and minimum heights of the cross section to the initial height of the ring blank [4-8].

Rolling tests have shown that rotational and linear speeds of the main roll have significant impact on the shape and dimensions of the cross section of the workpiece in the radial ring rolling process. The literature review has shown that there exist studies investigating the effect of velocity parameters on different aspects of rolling processes. The majority of the studies are devoted to the radial-axial ring rolling process.

Uchibori et al. [9] investigated the circumferential speed of a steel ring during hot ring rolling. They examined a radial-axial ring rolling process for a steel ring with a rectangular section. The process was conducted using different feed speeds of the mandrel. It was found that reduced ring width per revolution led to increased ring height in the circumferential direction, which could cause increase in product ovality. That observation was explained by the fact that decreased ring width led to increased ring height. It was also observed that the circumferential speed of the workpiece was similar to that of the main roll; however, the speed would decrease with a progress of the rolling process. In addition to that, it was observed that at the beginning of the rolling process the rotational speed of the ring was slightly faster than the circumferential speed of the main roll; after that, the speed would gradually decrease and - toward the end of the rolling process - it was lower than the circumferential speed of the main roll. Toward the end of the rolling process, ring slipping relative to the main roll decreased with increase in the ratio between mandrel feed speed and rotational speed of the main roll. The ratio also affected ring ovality, as increase in the ratio led to increase in ring ovality. The authors proposed using a relatively low ratio value in order to meet dimensional tolerance requirements.

Allegri et al. [10] investigated the effects of rotational speed of the main roll in the radialaxial ring rolling process. The FEM results demonstrated that a constant rotational speed of the main roll caused the rotational speed of the ring to decrease. Such kinematics of the process led to the formation of a cross shape defect known as "fishtail", as well as to great height and width deviations in produced rings. The authors proposed a new approach based on maintaining constant angular velocity of the workpiece via continuous change in rotational speed of the main roll. Such kinematic conditions can help reduce the abovementioned cross section defect of the rolled ring.

Yan et al. [11] investigated the effects of feed speeds $\left(V_{l}\right.$ or $V_{t}$, Fig. 1) in cold ring rolling. Using MATLAB, they developed a mathematical model describing the relationship between increase rate in ring outside diameter and feed speed of 
the mandrel. Also, the maximum and minimum values of the above velocities were determined in terms of process stability. The developed mathematical model was verified via stand testing. It was found that constant tool feed speed did not lead to the required dimensional tolerance of products. The mandrel feed speed $V_{t}$ was calculated based on the required increase rate for outside diameter of the ring. With such assumption it was possible to obtain products within dimensional tolerance. The authors found that the relationship between ring outside diameter increase and feed speed was non-linear. To ensure uniform and stable ring increase, the outside diameter increase rate had to be maintained constant, while the feed speed had to be reduced with decrease in ring thickness.

Giorleo et al. [7] investigated the effects of ring rolling process parameters, including mandrel feed speed and main roll rotational speed, on the cross section shape and the formation of a defect known as "fishtail". A FEM analysis was performed using DEFORM. They investigated the radial-axial ring rolling process; however, they observed that the conical rolls reduce the fishtail defect, therefore these rolls were not included in the numerical model. These authors also investigated the effects of a ratio of mandrel feed speed to main roll rotational speed on the formation of the above-mentioned defect. They employed optimisation techniques in order to determine process conditions ensuring minimal cross sectional defects, reduced rolling time and force parameters.

Kyung-Hun and Byung-Min in [12] found that, among others, higher ring diameter increase rate led to greater material strain uniformity in radial-axial ring rolling, and thus to smaller cross sectional defects. It was demonstrated that the "fishtail" coefficient decreased with increase in ring outside diameter increase rate. The study was conducted via numerical simulation of AISI 1035 steel ring rolling. The numerical results were then compared with experimental findings, which showed satisfactory agreement between them.

Lin and Zhi [13] used a numerical model to determine, among others, minimum and maximum feed speeds of the mandrel, as well as tool penetration depth during a single revolution of the ring ensuring stability of the rolling process. Based on the numerical analysis, they also determined maximum tool dimensions and maximum ring thickness.
Gontarz and Surdacki in [14] investigated the problem of slipping in radial ring rolling. Based on analysis of ring cross section reduction, they found that it was possible to predict slipping. The occurrence of this undesired phenomenon depended on the ratio of circumferential speed to feed speed of the main roll. Experimental results showed that ring thickness reduction and slipping probability increased with increase in the ratio of feed speed to circumferential speed of the main roll.

Yang et al. [6] investigated a cold ring rolling process, finding that rolled ring quality was significantly affected by velocity parameters of the forming process. The key forming parameters were rotational speed of the main roll and feed speed of the mandrel. The radial-axial ring rolling process was 3D simulated using ABAQUS. The following were analysed: fishtail coefficient, cross section defect, rolling force, and torque on the main roll. The results demonstrated that increase in rotational speed of the main roll led to increase in cross-sectional defect, whereas increase in feed speed of the mandrel led to the formation of a more rectangular cross section (smaller fishtail defect).

Liang-gang Guo and He Yang [8] investigated the effect of main roll and mandrel diameters in a cold ring rolling for aluminium alloy rings. The study involved performing FEM simulations in ABAQUS. It was found that changes in tool diameters lead to changes in shape and size of deformation zone in the roll gap. That had a significant impact on metal flow and ring quality. The results showed that increasing main roll diameter up to a certain value led to increased cross-sectional defect, with a reverse trend observed after exceeding the maximum value. On the other hand, increased mandrel diameter led to reduced cross-sectional defect; after exceeding the minimum value, further increase in mandrel diameter led to increased cross-sectional defect.

Similar studies were conducted by Anjami and Basti [15], who investigated the effect of tool diameter on selected aspects of the hot ring rolling process. A theoretical analysis was conducted using ABAQUS. FEM numerical simulations helped determine the effect of rolling tool diameters on the distribution of strain, temperature and stress, as well as on cross section defects. The results showed that there existed the optimal diameter of the mandrel and main roll which ensured the required distributions of stress and ring temperature, as well as the desired values of fishtail coefficient and force parameters. 
Luo et al. [16] investigated the effect of rotational speed of the main roll in the hot radial-axial ring rolling process for AZ31 alloy rings. The study was performed by numerical modelling. The results demonstrated that increased rotational speed of the main roll $n_{l}$, led to less uniform strain distribution in the rolled ring, while the temperature distribution became more uniform. These authors also analysed the fishtail coefficient, finding that this parameter initially decreased with increased rotational speed of the main roll, but then - after reaching the minimum value - it began to increase. This observation differs from other results, e.g. those reported in [6].

The literature review shows that tool speed parameters have a considerable effect on the ring rolling process, particularly on ring geometry. The primary failure mode is the so-called "fishtail", which is a cross-sectional defect. Only one cross-sectional dimension can be controlled in radial ring rolling, i.e. the final width, which is the distance between the active surfaces of the main roll and mandrel, measured after stopping linear tool motion. As for the other crosssectional dimension, i.e. height, this dimension is not controlled and metal flow is unconstrained, in contrast to the radial-axial ring rolling process wherein conical rolls are used to that end. The lack of control over cavity height means that it is impossible to control ring cross-sectional area and, thus, final product diameter. Consequently, compared to other process, the radial ring rolling process is conducted with relatively considerable material allowance in order to ensure that finished product diameter comply with that of a rolled forging [17]. Therefore, the design of an effective ring rolling process requires knowing the relationship between process parameters and rolled ring dimensions. Results of previous studies on this problem are not comprehensive due to several reasons:

- most of them were obtained from numerical simulations [18-23] or were verified via single experiments $[9,11,12]$,

- the accuracy of numerical modelling of ring rolling process is lower than that for other standard forming processes [23], due to the small area and the continuous change of contact between the material and the tools in the rolling process,

- the effect of velocity parameters on ring geometry is ambiguous due to the differences in obtained results, e.g. [6] and [16]. Some researchers [6] claim that when the rotational speed (n) of the main roll decreases, the fishtail coefficient increases. Others [16] believe with increasing $\mathrm{n}$, the ring fishtail ratio first decreases and then increases,

- there is lack of studies on the relationship between process effectiveness and cross section defects.

In light of the above, it was found justified to investigate the radial ring rolling process in order to:

- determine the relationship between linear feed rate of the main roll and ring geometry quality based on, among others, full experimental tests (literature review shows lack thereof),

- determine the modelling accuracy of specialist FEM-based simulation programs, i.e. Deform 2D/3D Ver. 11, Simufact.Forming 2021 and Forge NxT. 1.1,

- determine the effect of velocity parameters on radial ring rolling efficiency measured as a material consumption index.

\section{RESEARCH METHODOLOGY}

The research was conducted via experimental and theoretical method. Tests were conducted using the C45 (1.0503) grade steel billets with the chemical composition presented in Table 1. In the experiments a commercial rolling mill D51Y$160 \mathrm{E}$ was used (Fig. 2a). The beginning of the process with a hot billet put in the rolling gap is shown in Figure $2 b$.

The experiments were conducted using the following variables:

- feed speed of the main roll $V_{1}=5 \mathrm{~mm} / \mathrm{s}, 10$ $\mathrm{mm} / \mathrm{s}, 15 \mathrm{~mm} / \mathrm{s}, 20 \mathrm{~mm} / \mathrm{s}, 25 \mathrm{~mm} / \mathrm{s}, 30 \mathrm{~mm} / \mathrm{s}$, $35 \mathrm{~mm} / \mathrm{s}$ and $40 \mathrm{~mm} / \mathrm{s}$,

- constant rotational speed of the main roll $n_{1}=$ $60 \mathrm{rpm}$.

Table 1. Chemical composition of C45 (1.0503) grade steel [\% wt]

\begin{tabular}{|c|c|c|c|c|c|c|c|c|c|c|c|}
\hline $\mathrm{C}$ & $\mathrm{Mn}$ & $\mathrm{Si}$ & $\mathrm{P}$ & $\mathrm{S}$ & $\mathrm{Cr}$ & $\mathrm{Ni}$ & $\mathrm{Mo}$ & $\mathrm{W}$ & $\mathrm{V}$ & $\mathrm{Al}$ & $\mathrm{Cu}$ \\
\hline $0.42-0.5$ & $0.5-0.8$ & $0.1-0.4$ & $\begin{array}{c}\max \\
0.04\end{array}$ & $\begin{array}{c}\text { max } \\
0.04\end{array}$ & $\max 0.3$ & $\max 0.3$ & $\max 0.1$ & - & - & - & $\max 0.3$ \\
\hline
\end{tabular}


(a)

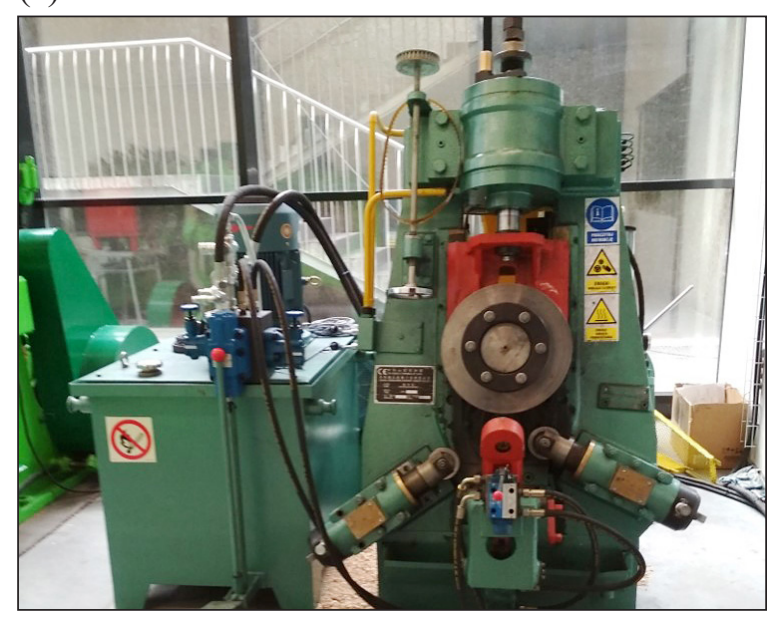

(b)

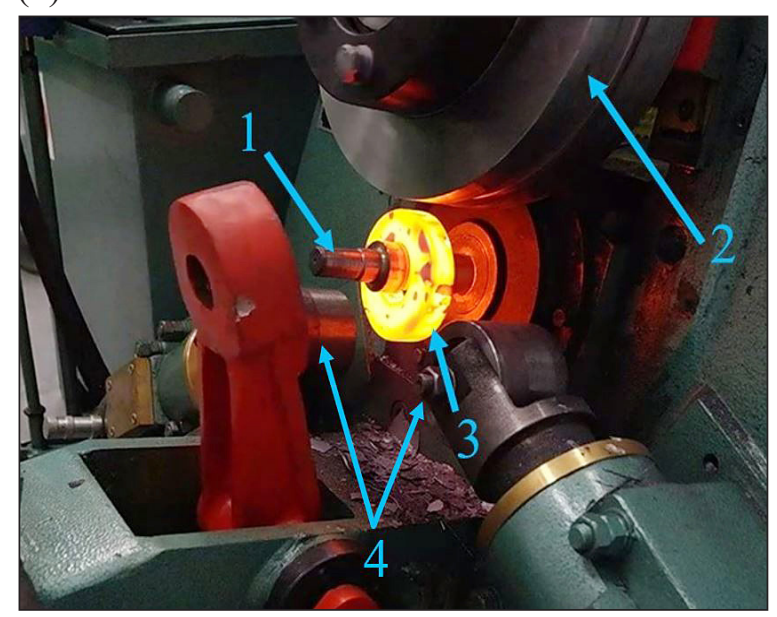

Fig. 2. D51Y-160E rolling mill used in experiments (a) and the initial stage of the rolling process conducted with the following tools (b); 1 - mandrel, 2 - main roll, 3 - ring, 4 - calibrating rolls

After stopping linear motion of the main roll $\left(V_{l}=0\right)$, rotational motion of the main roll is continued to ensure the ring is calibrated over its circumference.

Given previous results [7], which demonstrate that the ring rolling process is significantly affected by the relationship between linear feed and circumferential speed of the main roll, a speed ratio $k$ is introduced, defined as:

$$
k=\frac{V_{1}}{V_{c}}
$$

where: $V_{1}$-feed speed of the main roll in $\mathrm{mm} / \mathrm{s}$, $V_{c}$ - circumferential velocity of the main roll in $\mathrm{mm} / \mathrm{s}, V_{c}=\frac{D \pi n_{1}}{60}$,

$n_{1}$ - rotational speed of the main roll in rpm,

$D$ - diameter of the main roll in $\mathrm{mm}$.

Table 2 gives the velocity parameters used in the experiments. Ring-shaped billets had the following dimensions: outside diameter $D_{0}=102.5$ $\mathrm{mm}$, inside diameter $d_{0}=50 \mathrm{~mm}$, width $W_{0}=18$

Table 2. Velocity parameters applied in ring rolling experiments

\begin{tabular}{|c|c|c|c|}
\hline$V_{1}, \mathrm{~mm} / \mathrm{s}$ & $n_{1}, \mathrm{rpm}$ & $V_{c} \mathrm{~mm} / \mathrm{s}$ & $k,-$ \\
\hline 40 & 60 & 1193.2 & 0.0335 \\
\hline 35 & 60 & 1193.2 & 0.0293 \\
\hline 30 & 60 & 1193.2 & 0.0251 \\
\hline 25 & 60 & 1193.2 & 0.0210 \\
\hline 20 & 60 & 1193.2 & 0.0168 \\
\hline 15 & 60 & 1193.2 & 0.0126 \\
\hline 10 & 60 & 1193.2 & 0.0084 \\
\hline 5 & 60 & 1193.2 & 0.0042 \\
\hline
\end{tabular}

$\mathrm{mm}$. Before rolling, the samples were heated in an electric resistance furnace to $1100^{\circ} \mathrm{C}$ for $t=20$ min. Next, the billets were rolled with the required speeds until the cross-sectional width (the distance between the active surfaces of the main roll and mandrel) was $W_{f}=13 \mathrm{~mm}$. Tools with flat active surfaces used in the rolling process are schematically presented in Figs. 3a and 3b. In the tests, rotational speed and feed speed of the main roll, as well as the dimensions of the rolled ring were measured. Additionally, the samples were weighed after the rolling process in order to determine material volume losses due to sizing. The losses were calculated to be $2 \%$.

All the experiments were also verified via numerical analyses, with the dimensional, speed and temperature conditions maintained the same. As mentioned above, previous research conducted by the authors [24] indicated that commercial programmes for analysing metal forming processes had numerous limitations leading to reduced accuracy of results. For comparative purposes, three specialist FEM-based simulation programs were used: Deform 2D/3D Ver. 11.0. Simufact.Forming 2021 and Forge NxT 1.1. The friction phenomenon is described in the shear friction model, in which the friction factor is $m=0.75$. A comparative criterion was taken as the agreement between numerical and experimental dimensions of the rolled ring. This criterion was described by a function expressing the relative percentage difference between experimental and numerical ring dimensions:

$$
\Phi_{M E S}=\frac{1}{n} \sum_{i=1}^{n} \frac{\left|L_{M E S}-L_{\text {exp }}\right|}{L_{\text {exp }}} \cdot 100 \%,
$$



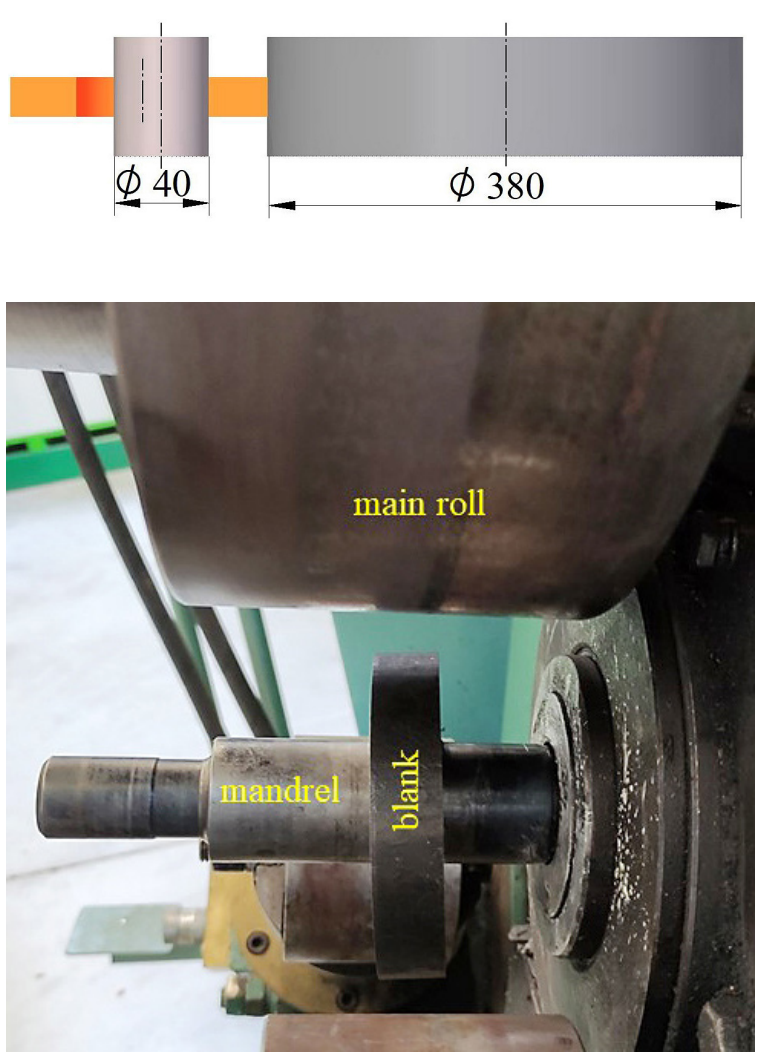

Fig. 3. Schematic (a) and real view (b) of the radial ring rolling process

where: $L_{M E S}-$ the numerical dimension under analysis,

$L_{\text {exp }}$ - the experimental dimension under analysis,

$i$ - the index,

$n$ - the number of dimensions under analysis.
The following dimensions $L_{M E S}$ and $L_{\exp }$ were analysed: outside diameter $D_{f}$, inside diameter $d_{f}$, minimum cross section height $H_{\text {min }}$, maximum cross section height $H_{\max }$ (Fig. 4). Therefore, the number $n$ was set to 4 .

The best simulation tool for a given case was that which ensured the lowest value of function (2).

Each of the simulations programs used had a specialist module for ring rolling simulation. In every case, the model of C45 (1.0503) grade steel was obtained from the material database library of the program used.

Other parameters used in the simulation are given in Table 3.

Numerical results were compared with the results of experimental testing with respect to certain aspects of the ring rolling process.

Table 3. Process parameters used in the numerical simulation

\begin{tabular}{|l|c|}
\hline \multicolumn{1}{|c|}{ Parameter } & Value \\
\hline Diameter of the main roll $\left[D_{m r}\right]$ & $380 \mathrm{~mm}$ \\
\hline Mandrel diameter $\left[D_{m}\right]$ & $40 \mathrm{~mm}$ \\
\hline Rotational speed of the main roll $\left[n_{1}\right]$ & $60 \mathrm{rpm}$ \\
\hline Feed speed of the main roll $\left[V_{1}\right]$ & $5 \mathrm{~mm} / \mathrm{s} \div 40 \mathrm{~mm} / \mathrm{s}$ \\
\hline Billet temperature & $1100^{\circ} \mathrm{C}$ \\
\hline Tool temperature & $150^{\circ} \mathrm{C}$ \\
\hline Temperature of the environment & $20^{\circ} \mathrm{C}$ \\
\hline Heat transfer to the tools & $10000 \mathrm{~W} \mathrm{~m}^{-2} \mathrm{~K}^{-1}$ \\
\hline Heat transfer to the environment & $10 \mathrm{~W} \mathrm{~m}^{-2} \mathrm{~K}^{-1}$ \\
\hline Friction factor & 0.75 \\
\hline
\end{tabular}
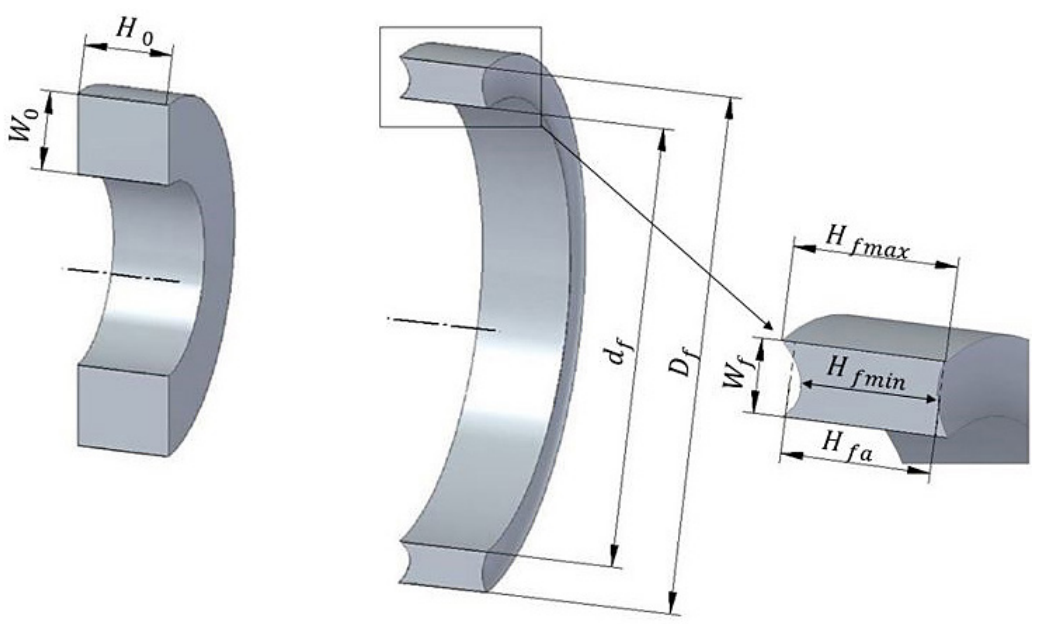

Fig. 4. Schematic of the ring cross-section before (a) and after (b) the rolling process; $\mathrm{W}_{0}-$ initial width of the ring, $\mathrm{H}_{0}$ - initial height of the ring, $\mathrm{H}_{\mathrm{f}}$ - final height of the ring, $\mathrm{H}_{\text {fmax }}$ - final maximum height of the ring, $\mathrm{H}_{\text {finin }}$ - final minimum height of the ring, $\mathrm{H}_{\mathrm{fa}}-$ final average height of the ring 


\section{RESULTS AND ANALYSIS}

\section{FEM analysis accuracy estimation}

The accuracy of FEM results was assessed with the use of three specialist simulation programmes. The ring rolling process under analysis was performed with a rotational speed of $n_{l}=60 \mathrm{rev} / \mathrm{min}$ and a feed speed of $V_{1}=5 \mathrm{~mm} / \mathrm{s}$. In the experiments, such velocity parameters led to a visible fishtail effect, which was considered favourable in terms of calculational accuracy. Ring shape obtained in the numerical simulations is shown in Figure 5. For all simulated cases, the numerical calculations proceeded in a stable manner, no numerical errors occurred to disrupt operation of the program. The rings are round in shape and have a distinctive hourglassshaped cross section (,fishtail") over their circumference. This shape agrees with the experimental one.

Table 4 gives the numerical and experimental ring dimensions and the values of function (2). A comparison of the numerical and experimental data demonstrates that for all cases, the numerical minimum height $H_{\min }$ and maximum height $H_{\max }$ are higher than the experimental ones. This means that, in the numerical simulation, there is rapid axial flow of material, which leads to increased ring height. Circumferential metal flow is constrained, and thus the numerical ring diameter is smaller than the real one. A comparison of the values of function (2) has revealed that the lowest average relative deviation of the theoretical dimensions from the experimental ones was obtained with $\mathrm{Si}$ mufact.Forming 2021. This simulation software was therefore used for further theoretical analyses. Regarding function (2) which equals $\Phi_{M E S}=$ $7.45 \%$, it should be noted that the value is relatively high. For that reason, it was decided that FEM analysis would be employed to establish qualitative relationships, i.e. to establish trends
Table 4. Comparison of experimental and numerical ring dimensions

\begin{tabular}{|c|c|c|c|c|}
\hline$D_{f}[\mathrm{~mm}]$ & $D_{f}[\mathrm{~mm}]$ & $H_{\min }[\mathrm{mm}]$ & $H_{\max }[\mathrm{mm}]$ & $\Phi_{\text {MES }}[\%]$ \\
\hline \multicolumn{5}{|c|}{ Experiment } \\
\hline 147.5 & 121.5 & 18.5 & 20.90 & \\
\hline \multicolumn{5}{|c|}{ Simufact. Forming 2021} \\
\hline 141.00 & 115.00 & 20.20 & 23.17 & 7.45 \\
\hline \multicolumn{5}{|c|}{ Forge NxT. 1.1 } \\
\hline 137.10 & 111.10 & 20.50 & 23.70 & 9.95 \\
\hline \multicolumn{5}{|c|}{ Deform 2D/3D Ver. 11} \\
\hline 127.80 & 101.80 & 22.50 & 27.60 & 20.81 \\
\hline
\end{tabular}

in the relationships between process parameters, whereas quantitative relationships would be determined via experimental testing.

\section{Relationship between main roll feed speed and ring geometry}

The effect of feed speed on ring geometry was investigated numerically using Simufact.Forming 2021 and tested experimentally. Figs. 6 and 7 show the experimental and numerical cross sections of rings obtained using different values of the feed speed $V_{r}$. The numerical and experimental results agree in terms of cross section shape. It can be observed that increase in $V_{1}$ causes reduction in cross-sectional shape non-uniformity, i.e. the higher the feed speed $V_{l}$ is, the more rectangular the cross section shape becomes.

Figure 7 shows the strain distribution in the section of the rings rolled with the feed speed ranging $5-35 \mathrm{~mm} / \mathrm{rev}$. It can be observed that the highest strain values are located near the material-tool contact surface, both from the side of the main roll and the mandrel. Increased local material flow results in increased height of the ring cross section in the contact areas compared to the height
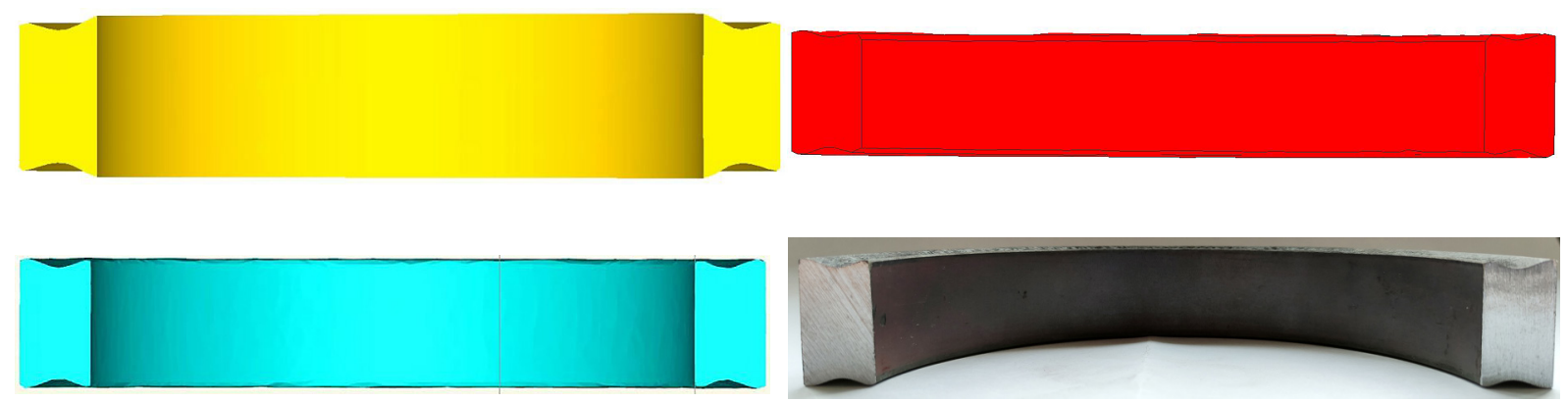

Fig. 5. Numerical results of the ring rolling process conducted with $n_{1}=60 \mathrm{rev} / \mathrm{min}$ and $V_{1}=5 \mathrm{~mm} / \mathrm{s}$, as simulated by: (a) Deform 2D/3D Ver. 11.0, (b) Simufact.Forming 2021, (c) Forge NxT 1.1. and obtained in experiment (d) 


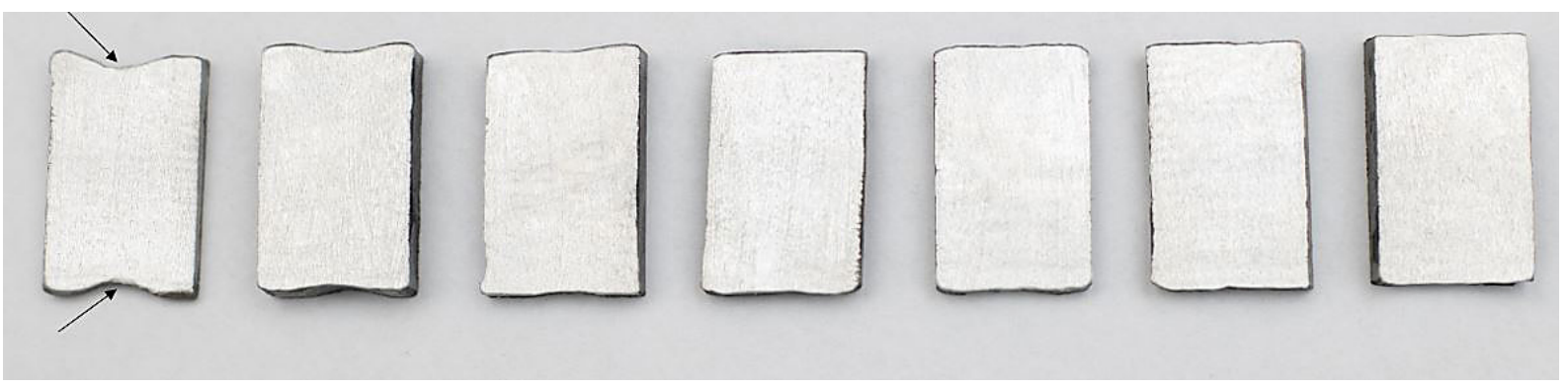

Fig. 6. Shape of the cross-section of the ring manufactured from billets with an initial width of $\mathrm{W}_{0}=18 \mathrm{~mm}$ using the following feed speeds: (a) $5 \mathrm{~mm} / \mathrm{rev}$, (b) $10 \mathrm{~mm} / \mathrm{rev}$, (c) $15 \mathrm{~mm} / \mathrm{rev}$, (d) 20 $\mathrm{mm} / \mathrm{rev}$ (e) $25 \mathrm{~mm} / \mathrm{rev}$, (f) $30 \mathrm{~mm} / \mathrm{rev}$, (g) $35 \mathrm{~mm} / \mathrm{rev}$; the arrows indicate the fishtail defect

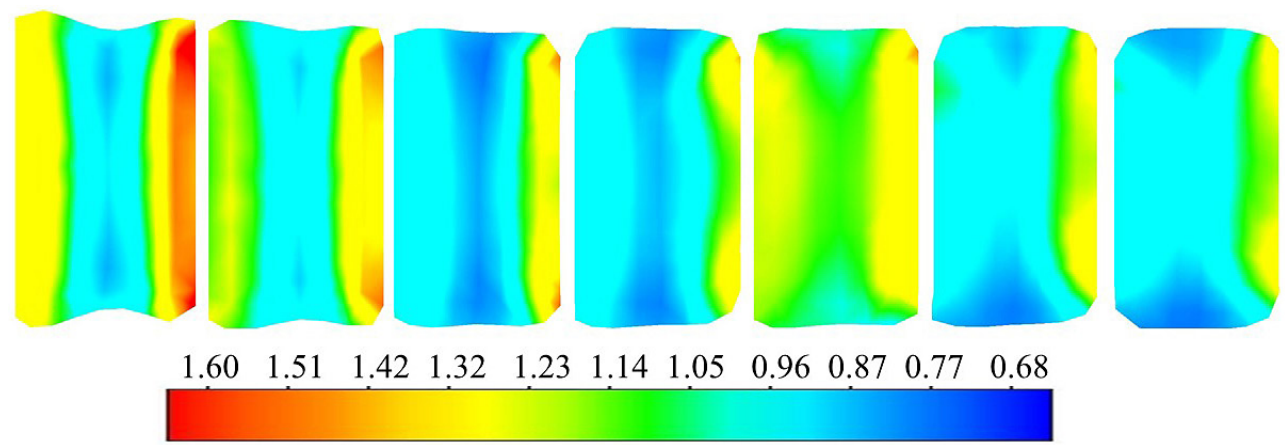

Fig. 7. Shape of the cross section and strain distribution obtained in the numerical simulation performed using billets with an initial width of $\mathrm{W}_{0}=18 \mathrm{~mm}$ and a feed speed of: (a) $5 \mathrm{~mm} / \mathrm{rev}$, (b) $10 \mathrm{~mm} / \mathrm{rev}$, (c) $15 \mathrm{~mm} / \mathrm{rev}$, (d) $20 \mathrm{~mm} / \mathrm{rev}$, (e) $25 \mathrm{~mm} / \mathrm{rev}$, (f) $30 \mathrm{~mm} / \mathrm{rev}$, (g) $35 \mathrm{~mm} / \mathrm{rev}$

in the centre of the cross section width. The strain distribution in the cross-section is more uniform for the feed speed $V_{l}=35 \mathrm{~mm} / \mathrm{s}$, which results in reduced cross-sectional defects.

In light of the above relationships, it can be stated that the application of the highest tested feed speed and speed ratio is favourable. It is, however, to be stressed that the speed ratio may not exceed the limit value. Should the speed ratio exceed the limit value, slipping may occur and, as a result, a defective product will be obtained. For the analysed rolling process, the use of $V_{l}=40$ $\mathrm{mm} / \mathrm{s}$ led to the occurrence of slipping and - as a result - to the formation of a product defect shown in Figure 8. It can, therefore, be claimed that for the analysed process, $V_{l}=35 \mathrm{~mm} / \mathrm{s}$ is the limit value which ensures that the process will proceed in a stable manner. It would be more adequate to relate the boundary conditions to the speed ratio $k$ defined by Equation (1), because it also considers the rotational speed $n_{l}$ and the diameter $D$ of the main roll. It can hence be stated that, for the analysed case, the limit speed ratio is $k_{\text {limit }}=0.0293$.

For quantitative assessment of the rolled part shape and dimensions, the following coefficients were defined.

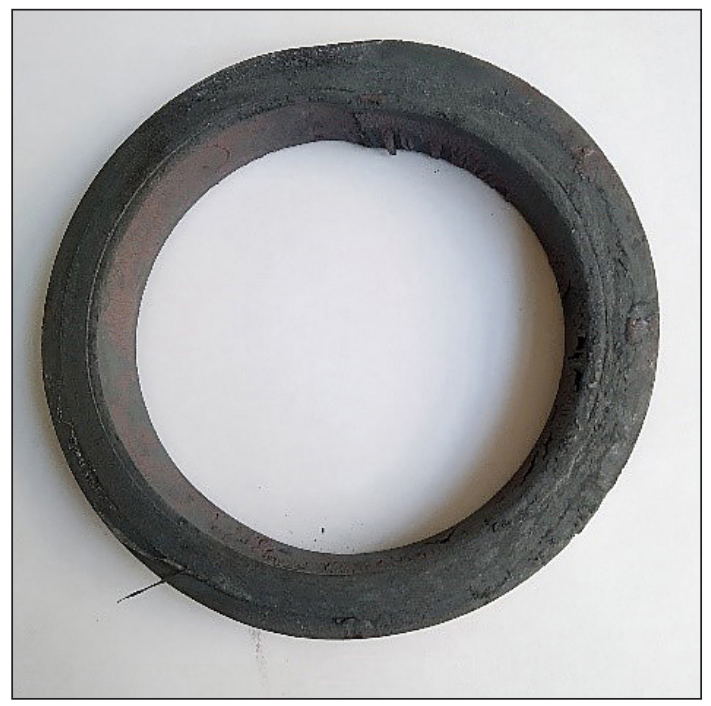

Fig. 8. Ring with a defect, as formed in the rolling process conducted with a feed speed of $40 \mathrm{~mm} / \mathrm{rev}$

During the rolling process, the material flows circumferentially and axially. Circumferential flow causes the diameter of the rolled product to increase, whereas axial flow causes the height of the section of the ring to increase (Fig. 4). The change to the height may be described using the 
coefficient called as widening, described by the following dependence:

$$
\alpha=\frac{H_{f a}-H_{0}}{H_{0}} * 100 \%,
$$

where: $H_{0}$ - the initial height of the billet in $\mathrm{mm}$, $H_{f a}$ - the average height of the cross section after rolling in $\mathrm{mm}$.

The widening coefficient is also applied for analysis of other rolling processes. Its value shows the tendency of material to axial flow during rolling. The higher the value of the widening coefficient $\alpha$ is, the more material volume is likely to flow axially and, as a result, a ring with a smaller diameter is obtained. Due to the fact that the height of the cross section is not constant (nonrectangular cross section), the average height was applied, expressed as:

$$
H_{f a}=\frac{4 * V_{f}}{\pi *\left(D_{f}^{2}-d_{f}^{2}\right)}
$$

where: $V_{f}-$ the volume of the ring after rolling in $\mathrm{mm}^{3}$,

$D_{f}$ - the outside diameter of the ring after rolling in $\mathrm{mm}$,

$d_{f}-$ the inside diameter of the ring after rolling in $\mathrm{mm}$.

For quantitative assessment of the cross section defect, the fishtail coefficient was used. The coefficient was modified by relating the difference between maximum and minimum cross-sectional heights not to the initial height but to the mean cross-sectional height defined in Equation (4). It was decided that such measure would be more objective than the one proposed in the literature [6-8], which describes a rolling case with a rectangular cross section (no fishtail defect).
The afore-mentioned coefficient can be defined by the following dependence:

$$
\beta=\frac{H_{\text {fmax }}-H_{f \min }}{H_{f a}} * 100 \%,
$$

where: $H_{f m a x}$ - the maximum height of the cross section in $\mathrm{mm}$,

$H_{f m i n}$ - the minimum height of the cross section in $\mathrm{mm}$,

$H_{f a}$ - the average height of the cross section in $\mathrm{mm}$.

For the case when the final cross section is rectangular, the $\beta$ coefficient is equal to 0 . The greater its value is, the more significant the crosssectional defect becomes (the so-called fishtail defect is visible).

Figure 9 shows the relationships between the coefficients $\alpha$ and $\beta$ and the feed speed $V_{1}$ and speed ratio $k$. Regarding the $\alpha$ coefficient, the dependence is linearly increasing, i.e. the higher the feed speed $V_{l}$ and the speed ratio $k$ are, the greater the $\alpha$ widening value becomes. That means that with higher ratio of feed speed to circumferential speed (rotational speed) of the main roll, the axial flow of material is increased, while the circumferential metal flow is reduced. As a result, with increasing the speed ratio $k$, the inside and outside diameters of produced rings are decreased.

As for the coefficient $\beta$, its value exponentially decreases with increasing the feed speed $V_{l}$ and the speed ratio $k$. It can therefore be stated that the greater the cross-sectional widening $\alpha$ is, the smaller the coefficient $\beta$ becomes, and hence the fishtail defect is reduced. This can be observed in Figs. 6 and 7 showing the cross-sections of obtained rings. The rings were manufactured with

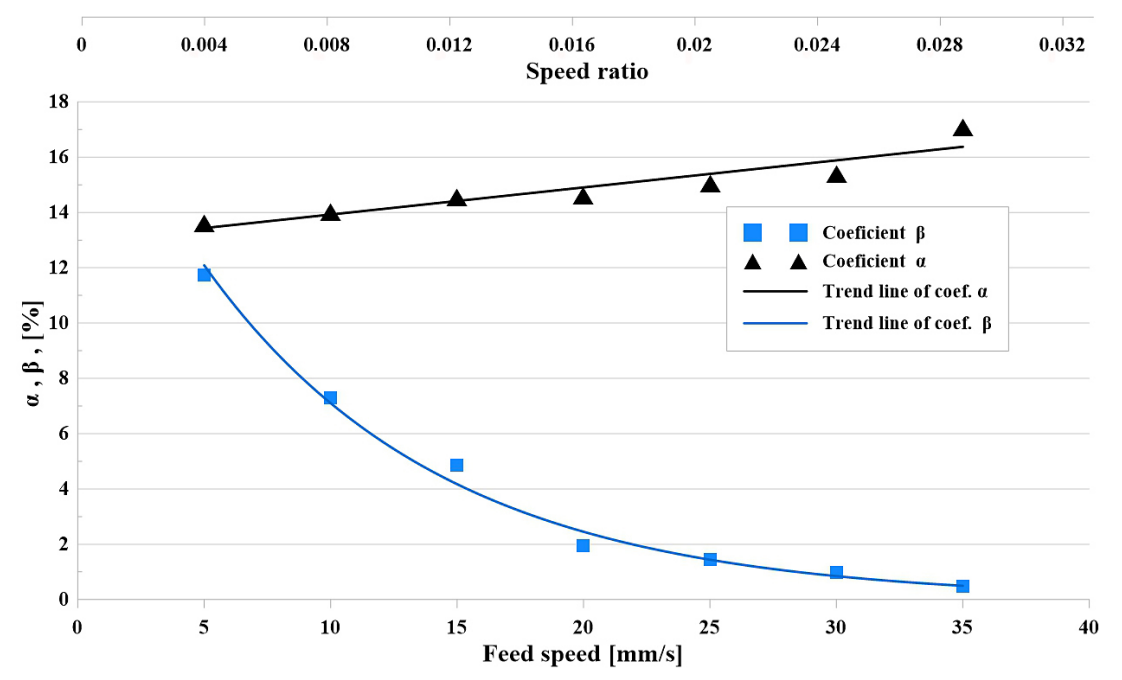

Fig. 9. Coefficients $\alpha$ and $\beta$ as a function of main roll feed speed $V_{1}$ and speed ratio $k$ - experimental results 
different values of $V_{l}$ and $k$. The greater the values of $V_{l}$ and $k$ are, the more rectangular the shape of the cross-section becomes. It is worth noting that after the speed ratio has exceeded the value of $k>0.017$, the coefficient $\beta$ is low and below $2 \%$. Consequently, it can be concluded that - due to cross-sectional defects - the analysed ring rolling process should be conducted with the velocity parameters for which $\mathrm{k}>0.017$.

\section{Material consumption of the rolling process}

The minimum height of the formed section, $H_{\text {finin, }}$ is of great significance for process effectiveness assessment. This dimension has impact on the obtainable height of the final product with a rectangular section after machining. The smaller the $H_{\text {fmin }}$ value is, the more material must be removed via machining. To assess material losses, a coefficient expressed by the following relationship was applied:

$$
\delta=\frac{V_{l}}{V_{0}} * 100 \%,
$$

where: $V_{0}$ - the initial volume of the billet in $\mathrm{mm}^{3}$. $V_{l}$ - the volume of material loss in machining in $\mathrm{mm}^{3}$, which can be calculated from the following dependence:

$$
V_{l}=V_{f}-\frac{\pi *\left(D_{f}^{2}-d_{f}^{2}\right) * H_{f m i n}}{4}
$$

The coefficient $\delta$ describes the percentage of material loss due to cross-sectional defects (fishtail defect). The higher the $\delta$ coefficient value is, the less effective the process becomes, that is the greater the material volume loss in machining.
Figure 10 illustrates the influence of feed speed $V_{l}$ and speed ratio $k$ on the coefficient $\delta$ (Equation (6)) describing material loss in machining due to cross-sectional defects. It can be observed that the higher the values of feed speed $V_{1}$ and speed ratio $k$ are, the less considerable the material volume loss becomes. For the tested feed velocities, the coefficient $\delta$ ranges from $9.5 \%$ for $V_{l}=5 \mathrm{~mm} / \mathrm{s}$ and $k=0.0042$ to $0.1 \%$ for $V_{l}=35$ $\mathrm{mm} / \mathrm{s}$ and $k=0.0293$. It can be observed that for the feed speed $V_{l}$ above $20 \mathrm{~mm} / \mathrm{s}$ (speed ratio $k$ is greater than 0.0168), the material loss does not exceed $1 \%$. That means that these values should be applied in order to reduce material loss. As for the remaining range of velocity parameters, material losses are relatively significant, considering the fact that rings are often manufactured in large series. The above phenomenon is also connected with the coefficient $\beta$; specifically, the more deformed the cross-section is (greater value of $\beta$ ), the more material must be removed via machining in order to obtain a ring with a rectangular section.

\section{CONCLUSIONS}

The results of the study on the hot radial ring rolling process for $\mathrm{C} 45$ (1.0503) grade steel rings lead to the following conclusions:

1. Acomparison of the numerical results (obtained with the use of three different commercial simulation programs) and experimental findings has shown that they agree in terms of quality (similar ring shapes) but there is poor quantitative agreement between them. The numerical

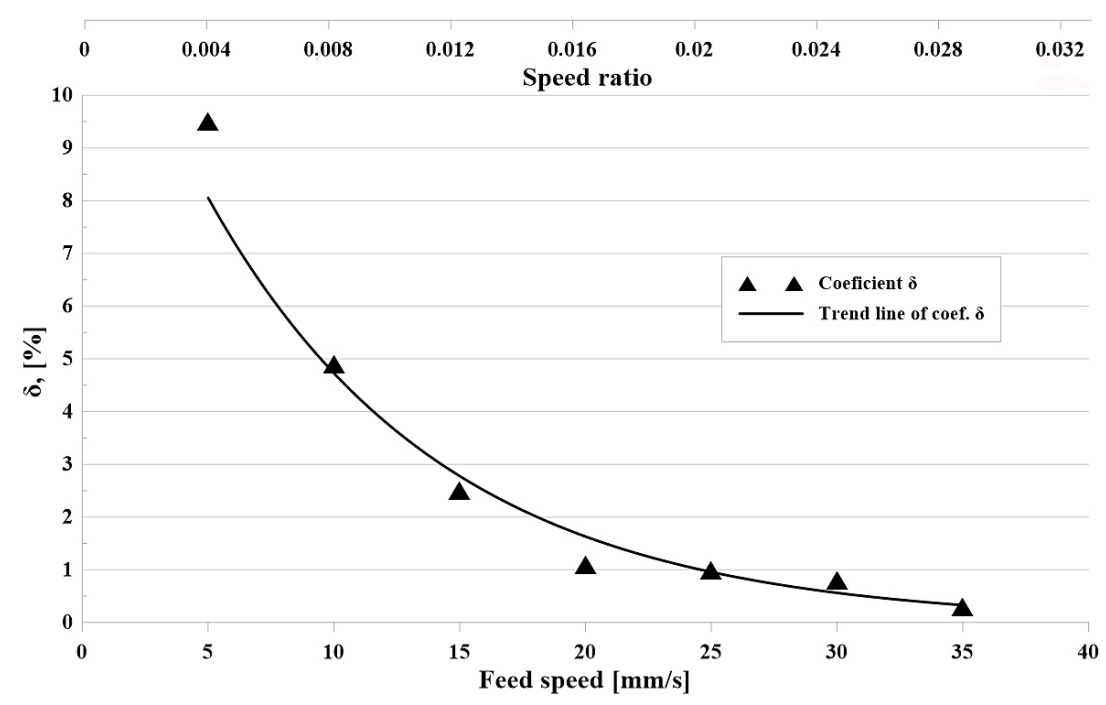

Fig. 10. Coefficient $\delta$ as a function of feed speed and speed ratio of the main roll 
results demonstrate that - irrespective of the simulation software applied - axial metal flow is increased and circumferential metal flow is lower than those obtained in the experiments. For the analysed case, the best results were obtained with Simufact.Forming 2021. Nevertheless, it can be concluded that experimental testing is the basic research method for investigating radial ring rolling processes.

2. Velocity parameters have a significant influence on the dimensions and shape of ring cross section and - as a result - on the outside and inside diameter of rolled rings. The knowledge of these relationships is essential when designing a rolling process for rings with specified dimensions. Moreover, it reduces the need for applying the trial and error method when launching the production of new elements.

3. With increasing speed ratio (feed speed to circumferential velocity ratio), the cross sectional widening of the rolled ring increases too, i.e. axial flow of material is increased while circumferential flow of material is reduced. For higher speed ratio values, the produced rings have smaller diameters.

4. The greater the speed ratio is, the smaller the cross-sectional defects and the smaller the fishtail defect become. As a result, if a rectangular cross section is required, the material loss for machining allowance due to cross-sectional defects is lower too.

5. It recommended that rolling processes similar to that described in this paper should be conducted with a speed ratio of $k>0.017$. In effect, the cross section will be almost rectangular and hence material loss due to cross-sectional defects will be below $1 \%$. When calculating rolled ring diameter, one should consider ring height increase ranging from 14.5 to $17.0 \%$.

\section{Funding}

The research was financed in the framework of the project Lublin University of TechnologyRegional. Excellence Initiative, funded by the Polish Ministry of Science and Higher Education (contract no. 030/RID/2018/19).

\section{REFERENCES}

1. Arbak M., Tekkaya A.E., Ozhan F. Comparison of various preforms for hot forging of bearing rings.
Journal of Materiels Processing Technology. 2005; 169: 72-82.

2. Drozdowski K., Tofil A., Gontarz A., Pater Z., Tomczak J. Manufacturing process of plane rim from aluminium alloy. Aircraft Engineering and Aerospace Technology. 2013; 85: 487-492.

3. Tofil A., Tomczak J., Bulzak T. Numerical and experimental study on producing aluminium alloy 6061 shafts by cross wedge rolling using a universal rolling mill. Archives of Metallurgy and Materials. 2015; 60: 801-807.

4. Eruc E., Shivpuri R. A summary of ring rolling technology-I. Recent trends in machines, processes and production lines. International Journal of Machine Tools and Manufacture. 1992; 32: 379-398.

5. Eruc E., Shivpuri R. A summary of ring rolling technology-II. Recent trends in machines, processes and production lines. International Journal of Machine Tools and Manufacture. 1992; 32: 399-413.

6. Yang H., Guo L., Zhan M., Sun Z. Research on the influence of material properties on cold ring rolling process by 3D-FE numerical simulation. Journal of Materials Processing Technology. 2006; 177: 634-638.

7. Uchibori T., Matsumoto R., Utsunomiya H. Peripheral speed of steel ring during hot ring rolling. Procedia Manufacturing, 2018; 15: 89-96.

8. Allegri G., Giorleoa L., Cerettia E., Giardin C. Driver roll speed influence in ring rolling process. Procedia Engineering. 2017; 207: 1230-1235.

9. Yan F.L., Lin H., Wuc Y.Q. Planning feed speed in cold ring rolling. International Journal of Machine Tools and Manufacture. 2007; 47: 1695-1701.

10. Giorleo L., Ceretti E. Investigation of the fishtail defect in ring rolling by a FEM approach. International Journal of Machine Tools and Manufacture. Proceedings of NAMRI/SME. 2012; 40,

11. Kyung-Hun L., Byung-Min K. Advanced feasible forming conditio for reducing rings preads in radial-axial ring rolling. International Journal of Mechanical Sciences. 2013; 76: 21-32

12. Lin H., Zhi Z.Z. The extremum parameters in ring rolling. Jouranal of Materials Processing Technology. 1997; 69: 273-276.

13. Gontarz A., Surdacki P. Investigation of Slip Occurrence in the Ring Rolling Process. MATEC Web of Conferences 291, St. Petersburg, Russian Federation 2019.

14. Ling-gang G., He Y. Effect of size of forming rolls on cold ring rolling by 3D-FE numerical simulation. Trans. Nonferrous Met. Soc. China, 2006; 16 : 645-651.

15. Anjami N., Basti A. Investigation of rolls size effects on hot ring rolling process by coupled thermomechanical 3D-FEA. Journal of Materials Processing Technology. 2010; 210: 1364-1377. 
16. Luo X., Li L., Xu W., Zhu Y. Effect of driver roll rotational speed on hot ring rolling of AZ31 magnesium alloy. Journal of Magnesium and Alloys. 2014; 2: 154-158.

17. ASM Metals Handbook. Forming And Forging. ASM International, 1993; 14.

18. Forouzan M.R., Salimi M., Gadala M.S. Threedimensional FE analysis of ring rolling by employing thermal spokes method. International Journal of Mechanical Sciences. 2003; 45: 1975-1998.

19. Jenkouk V., Hirt G., Franzke M., Zhang T. Finite element analysis of the ring rolling process with integrated closed-loop control. CRIP Annals - Manufacturing Technology. 2012; 64: 267-270.

20. Lim T., Pillinger I., Hartley P. A finite-element simulation of profile ring rolling using a hybrid mesh model. Journal of Materials Processing Technol- ogy. 1998; 80-81: 199-205.

21. Giorleo L., Ceretti E., Giardini C. Energy consumption reduction in ring rolling processes: A FEM analysis. International Journal of Mechanical Sciences. 2013; 74: 55-64.

22. Wang M., Yang H., Sun Z.C., Guo L.G. 3D coupled thermo-mechanical FE modeling of blank size effects on the uniformity of strain and temperature distributions during hot rolling of titanium alloy large rings. Computational Materials Science. 2008; 44: 611-621.

23. Banerjee P., Hui N.B. Finite element modeling of ring rolling process. Materials Today. 2017; 11: 843-848.

24. Surdacki P., Gontarz A. Comparative analysis of FEM models of ring rolling process. Hutnik Wiadomości Hutnicze. 2018; 85: 75-79. 